\title{
Cycloartan-24-ene-1 $\alpha, 2 \alpha, 3 \beta$-triol, a cycloartane-type triterpenoid from the resinous exudates of Commiphora myrrha, induces apoptosis in human prostatic cancer PC-3 cells
}

\author{
WENYAN GAO ${ }^{1}$, XIAOJIE SU $^{1}$, XIAOYAN DONG ${ }^{1}$, YINGLI CHEN $^{1}$, CHUNLAN ZHOU $^{1}$, \\ PING XIN ${ }^{1}$, CHUNHAO YU ${ }^{2}$ and TAIMING WEI ${ }^{1}$ \\ ${ }^{1}$ Department of Biopharmaceutical Sciences, College of Pharmacy, Harbin Medical University-Daqing, \\ Daqing, Heilongjiang 163000; ${ }^{2}$ School of Life Science and Chemical Engineering, \\ Huaiyin Institute of Technology, Huaian, Jiangsu 223003, P.R. China
}

Received September 8, 2014; Accepted September 29, 2014

DOI: $10.3892 /$ or.2015.3725

\begin{abstract}
Plant-derived antitumor drugs are currently used in chemotherapy. Cycloartane triterpenoids have shown a cytotoxic effect on human prostate cancer cells. The aim of the present study was to isolate a cycloartane triterpenoid from Commiphora myrrha and evaluate its anticancer potential. Cycloartan-24-ene-1 $\alpha, 2 \alpha, 3 \beta$-triol (MY-1) was isolated from Commiphora myrrha, and its structure was determined through ${ }^{1} \mathrm{H}$ and ${ }^{13} \mathrm{C}$ nuclear magnetic resonance spectroscopy. The cytotoxic and apoptotic effects of MY-1 on human prostatic cancer PC-3 cells were estimated by 3-(4,5-dimethylthiazol-2-yl)-2,5-diphenyltetrazolium bromide (MTT) assay, flow cytometric analysis and terminal deoxynucleotidyl transferase dUTP nick end-labeling (TUNEL) staining assay, and the expression of apoptotic-related proteins were evaluated by western blotting. MY-1 showed cytotoxic activity on PC-3 cells in a concentration-dependent manner with an $\mathrm{IC}_{50}$ value of $9.6 \mu \mathrm{M}$ at $24 \mathrm{~h}$. MY-1 induced cell cycle arrest and apoptosis. Western blot analysis revealed that MY-1 regulated the expression levels of B-cell lymphoma 2 (Bcl-2), Bcl-2-associated $\mathrm{X}$ protein (Bax), p53 and caspase- 3 in the PC-3 cells. These findings indicate that MY-1 exerts significantly pro-apoptotic activity against human hormone-independent prostatic cancer and support MY-1 as a potential anticancer drug.
\end{abstract}

\section{Introduction}

Apoptosis is an evolutionary conserved cellular suicide program first proposed in 1972 by Kerr et al (1). The characteristics of apoptosis include cell shrinkage, depolarization of

Correspondence to: Dr Taiming Wei, Department of Biopharmaceutical Sciences, College of Pharmacy, Harbin Medical UniversityDaqing, Daqing, Heilongjiang 163000, P.R. China

E-mail: wei032061451@163.com

Key words: cycloartan-24-ene-1 $\alpha, 2 \alpha, 3 \beta$-triol, PC-3, cycloartanes, apoptosis, Commiphora myrrha the mitochondria, condensation of chromatin, fragmentation of genomic DNA, membrane blebbing and the formation of apoptotic bodies, and these morphological changes make apoptosis obviously different from necrosis. In general, apoptosis occurs through two pathways: the death receptor pathway and the mitochondrial-dependent pathway. In the mitochondrialinitiated pathway, the loss of mitochondrial integrity is an important event (2). It has been clearly demonstrated that the mitochondrial membrane potential $(\Delta \Psi \mathrm{m})$ decreases during apoptosis (3). The intracellular cysteine protease of the caspase family, which is divided into two classes including initiators and effectors, is an important component of apoptosis (4). Caspase-3, one of the downstream executioner caspases, is widely recognized as a key member of the caspase family and its activation is a typical characteristic of apoptosis (5). Tumor-suppressor protein p53 is one of the major regulators of the apoptotic process in response to DNA damage from both endogenous and exogenous sources. p53 is involved in the regulation of B-cell lymphoma 2 (Bcl-2) and Bcl-2associated X protein (Bax) (6). Bcl-2, an anti-apoptotic protein present on the mitochondrial membrane, can block the release of cytochrome $c$ from mitochondria and prevent the activation of caspase- 9 by binding and inactivating pro-apoptotic Bax, preventing activation of the mitochondrial pathway (7). The expression of apoptotic regulatory proteins (p53, Bax and $\mathrm{Bcl}-2$ ) activates the initiator caspases which in turn directly activate the effector caspases such as caspase-3 (8). The activation of the caspase cascade leads to the cleavage of regulatory and structural proteins which results in the biochemical and morphological changes associated with apoptotic cell death. Apoptotic cell death is an essential process in the development and homeostasis of metazoans (9). The induction of apoptosis, which promotes cell death automatically without damage, is also a crucial strategy in anticancer drug research and development (10). Therefore, apoptosis has been used as a marker to evaluate the anticancer activities of phytochemical components during the development of potential anticancer drugs $(8,11)$.

Medicinal plants for the development of potential cancer chemopreventive or cancer therapeutic agents are important due to their minimal adverse side-effects and anti-multidrug 
resistance $(12,13)$. Previous studies have indicated that natural products are rich in anticancer compounds (14). Some plant-derived antitumor drugs such as paclitaxel, camptothecin, vincristine and vinblastine are used in cancer chemotherapy (15). The Commiphora genus in the family of Burseraceae, which consists of more than 150 species, is mainly distributed in Eastern Africa, Arabia and India $(16,17)$. This genus has been extensively researched due to its many different medicinal uses, and the large number of compounds that have been isolated from the plants show potential in the treatment of a wide range of diseases (18). Based on the theory of traditional Chinese medicine, the resinous exudates of $C$. myrrha have been applied for the treatment of blood stagnation and inflammatory diseases, as well as for the relief of swelling and pain (19). Phytochemical investigations have revealed that a series of terpenoids have been isolated from the resinous exudates of $C$. opobalsamum, including cycloartane-type triterpenoids, sesquiterpenoids, an aliphatic alcohol glycoside and a steroid (20-22). Some of these isolated compounds have been shown to possess cytotoxic and antiproliferative activities on several cancer cells, particularly the cycloartane-type triterpenoids $(23,24)$.

Prostate cancer is one of the most commonly diagnosed malignancies, with high incidence among elderly men (25-27). In China, the morbidity and mortality associated with prostate cancer are increasing. Androgen deprivation therapy is the major treatment for metastatic prostate cancer. Unfortunately, this form of treatment ultimately leads to the development of resistance to anti-androgen therapy and the continuation of tumor metastasis $(28,29)$. Therefore, it is critically important to develop novel anticancer agents for the treatment of androgen-independent prostate cancer. Many natural compounds with therapeutic potential for prostate cancers are widely found in herbal medicines, including flavonoids (30), lignans $(31,32)$, monoterpenoids $(33,34)$, diterpenoids $(35,36)$ and triterpenoids $(21,22,37,38)$. Some reported cycloartane-type triterpenoids $(21,22)$, including cycloartan24 -ene-1 $\alpha, 2 \alpha, 3 \beta$-triol (MY-1) from C. opobalsamum were found to have a cytotoxic effect on the human prostate cancer PC-3 cell line. However, the mechanism of apoptosis that cycloartane-type triterpenoids induce is still unclear.

In the present study, human prostate cancer PC-3 cells were selected to evaluate the cytotoxic effect of MY-1 from C. myrrha. Based on a previous report (24) that cycloartane triterpenoids induce the apoptosis of MCF-7 cells through the mitochondrial signaling pathway, we also investigated whether MY-1 induces apoptosis in PC-3 cells through the mitochondrial pathway.

\section{Materials and methods}

Plant materials. C. myrrha exudates were purchased in December 2009 from the Anguo medicinal material market, Daqing, China. This material was identified by Professor Taiming Wei of the Institute of Biological Pharmacy at Harbin Medical University in China. A voucher specimen (ZY089) was deposited in the Herbarium of the Institute.

Extraction and isolation. The C. myrrha exudates $(0.5 \mathrm{~kg})$ were pulverized and extracted with a 1-fold volume of $95 \%$ ethanol under reflux ( $3 \times 2 \mathrm{~h})$, and the solvent was evaporated under vacuum to obtain a residue. The residue was then suspended in $\mathrm{H}_{2} \mathrm{O}$ and extracted successively with petroleum ether (PE), chloroform, and ethyl acetate to yield PE-soluble, chloroform-soluble, and ethyl acetate-soluble fractions. The chloroform-soluble fraction was evaporated in vacuo to yield a residue (112.3 $\mathrm{g}$ ), and this residue was chromatographed on a silica gel column (63 g) and eluted with PE-ethyl acetate gradient with increasing amounts of ethyl acetate to obtain eight subfractions (Fr1-8). Fr7 (16.9 g) was divided into five fractions (F71-F75) using a silica gel column and eluted with a gradient of dichloromethane-methanol (100:0, 80:1, 40:1, 20:1 and 10:1). Fraction F73 was further purified to yield MY-1 (24.1 mg). The structure of MY-1 was identified through one dimensional nuclear magnetic resonance (1D NMR) spectroscopic methods.

Cell culture. The human prostate cancer cell line PC-3 was obtained from the American Type Culture Collection (ATCC; Rockville, MD, USA) and maintained in Roswell Park Memorial Institute (RPMI)-1640 medium supplemented with $10 \%$ fetal bovine serum (FBS; Hangzhou Sijiqing Biological Engineering Materials Co., Ltd., Zhejiang Deqing County, China) in a humidified incubator with an atmosphere of $95 \%$ air and $5 \% \mathrm{CO}_{2}$ at $37^{\circ} \mathrm{C}$.

Cytotoxicity assay. For the cytotoxicity assays in the PC-3 cells, the cells were seeded in 96-well plates at a density of $1 \times 10^{5}$ cells/well and incubated for $24 \mathrm{~h}$ at $37^{\circ} \mathrm{C}$ in a humidified $5 \% \mathrm{CO}_{2}$ atmosphere prior to testing. The old media were then replaced with fresh media containing various concentrations of the tested compounds or the vehicle, dimethyl sulfoxide (DMSO). After a 24-h incubation, $10 \mu \mathrm{l}$ of 3-(4,5-dimethylthiazol-2-yl)-2,5-diphenyltetrazolium bromide (MTT; Sigma-Aldrich, St. Louis, MO, USA) solution $[5 \mathrm{mg} / \mathrm{ml}$ in phosphate-buffered saline (PBS)] was added to each well, and the plates were then incubated at $37^{\circ} \mathrm{C}$ for an additional $4 \mathrm{~h}$. After incubation, the culture medium was replaced with $100 \mu \mathrm{l}$ of DMSO, the plates were shaken for $10 \mathrm{~min}$ to dissolve the crystals, and the absorbance of each well was measured using a microplate reader (Gen5; BioTek, Winooski, VT, USA) at a wavelength of $490 \mathrm{~nm}$. Briefly, the cell growth curves were generated by plotting the OD value of each point against the concentration. In each experiment, the determinations were performed at least three times.

Apoptosis assays. Flow cytometric analysis was employed to determine the apoptotic cells after treatment with various concentrations of MY-1 using an Annexin V-FITC/PI apoptosis detection kit (Beyotime Institute of Biotechnology, Shanghai, China). Briefly, the cells were seeded in 6-well plates and incubated for $24 \mathrm{~h}$. After treatment with 9.6 or 14.4 $\mu \mathrm{M}$ MY-1 for $24 \mathrm{~h}$, both adherent and floating cells were combined, subjected to a brief trypsinization, washed with PBS, and stained with Annexin V-FITC/propidium iodide (PI) according to the manufacturer's instructions. Cells in early apoptosis $\left(\mathrm{AV}^{+} / \mathrm{PI}^{-}\right.$, lower right quadrant) and late apoptosis eventually leading to secondary necrosis $\left(\mathrm{AV}^{+} / \mathrm{PI}^{+}\right.$, upper right quadrant) were discriminated from the primary necrotic cells $\left(\mathrm{PI}^{+}\right)$. 
TUNEL assay. The terminal deoxynucleotidyl transferase dUTP nick end-labeling (TUNEL) technique was used to detect the apoptotic morphological changes in PC-3 cells treated with MY-1 according to the manufacturer's instructions (Roche Diagnostics GmbH, Germany). Briefly, the cells were cultured on coverslides in 6-well plates, incubated overnight at $37^{\circ} \mathrm{C}$, and then treated with various concentrations of MY-1 for $24 \mathrm{~h}$. After an additional 24-h incubation, the cells were fixed in freshly prepared $4 \%$ paraformaldehyde-PBS ( $\mathrm{pH} 7.4$ ) for $20 \mathrm{~min}$ at room temperature. The cells were rinsed three times in the wells with $1 \mathrm{ml}$ of cold PBS on a shaker and blocked with $1 \mathrm{ml}$ of blocking solution $\left(3 \% \mathrm{H}_{2} \mathrm{O}_{2}\right.$ in methanol) in each well at room temperature for $10 \mathrm{~min}$. The cells were rinsed twice with PBS for $10 \mathrm{~min}$. Then, $1 \mathrm{ml}$ of permeabilization solution $(0.1 \%$ Triton $\mathrm{X}-100$ in $0.1 \%$ sodium citrate, freshly prepared) was added to each well of the monolayer of cells for $2 \mathrm{~min}$ at $4^{\circ} \mathrm{C}$. The cells were rinsed twice with PBS for $10 \mathrm{~min}$. Then, $50 \mu \mathrm{l}$ of the TUNEL reaction mixture was homogeneously spread across the cell monolayer, and the cells were incubated for $60 \mathrm{~min}$ at $37^{\circ} \mathrm{C}$ in a humidified atmosphere in the dark. After the cells were washed three times in PBS, $50 \mu 1$ of 4',6-diamidino-2-phenylindole (DAPI) solution was added for $5 \mathrm{~min}$ at room temperature. The samples were analyzed in a drop of PBS under a fluorescence microscope (Nikon TE2000).

Analysis of mitochondrial membrane potential $(\Delta \Psi m)$. The $\Delta \Psi \mathrm{m}$ was estimated by $\mathrm{JC}-1$ staining (Beyotime Institute of Biotechnology). JC-1 is one of the fluorescence probes that is most commonly used to detect $\Delta \Psi \mathrm{m}$. JC- 1 is able to cross the intact mitochondrial membrane to form aggregates in the mitochondrial matrix and give a red fluorescence when $\Delta \Psi \mathrm{m}$ is high, whereas the ungathered monomeric JC-1 produces a green fluorescence at lower $\Delta \Psi \mathrm{m}$. After treatment with various concentrations of MY-1 for $24 \mathrm{~h}$, the cells were harvested, suspended and then incubated with JC-1 dye according to the manufacturer's instructions. Subsequently, the cells were examined on a flow cytometer (BD FACSAria; Becton-Dickinson, Franklin Lanes, NJ, USA).

Cell cycle analysis. PC-3 cells were seeded in 6-well plates and treated with various concentrations of MY-1 for $24 \mathrm{~h}$. After treatment, both floating and adherent cells were collected, washed with cold PBS, and fixed overnight in $70 \%$ cold ethanol at $4^{\circ} \mathrm{C}$. After removing the ethanol, cells were washed twice with cold PBS and stained with $25 \mu \mathrm{l}$ PI and $10 \mu \mathrm{l}$ RNase A in the dark for $30 \mathrm{~min}$ at $37^{\circ} \mathrm{C}$. The DNA content of cells was analyzed by FACS flow cytometer (Becton-Dickinson).

Western blot analysis. PC-3 cells were grown for $24 \mathrm{~h}$ in the presence or absence of MY-1 $(9.6$ or $14.4 \mu \mathrm{M})$ at $37^{\circ} \mathrm{C}$. The total cell lysates were prepared after the various treatments. An equal amount of protein $(10 \mu \mathrm{l})$ was separated by sodium dodecyl sulfate-polyacrylamide gel electrophoresis (SDS-PAGE) and then electroblotted onto a nitrocellulose membrane. The membranes were incubated with TBS-Tween and 5\% fat-free dried milk for at least $1 \mathrm{~h}$ at room temperature to block any non-specific binding sites and then incubated with primary antibodies against Bcl-2, Bax, caspase-3 and p53, all of which were diluted in $5 \% \mathrm{BSA}$, overnight at $4^{\circ} \mathrm{C}$. All of the primary

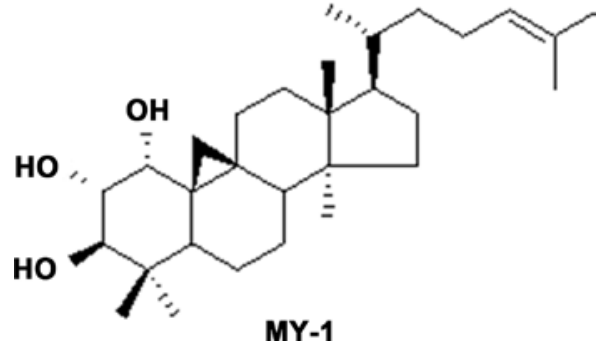

Figure 1. Chemical structural formula of cycloartan-24-ene-1 $\alpha, 2 \alpha, 3 \beta$-triol (MY-1).

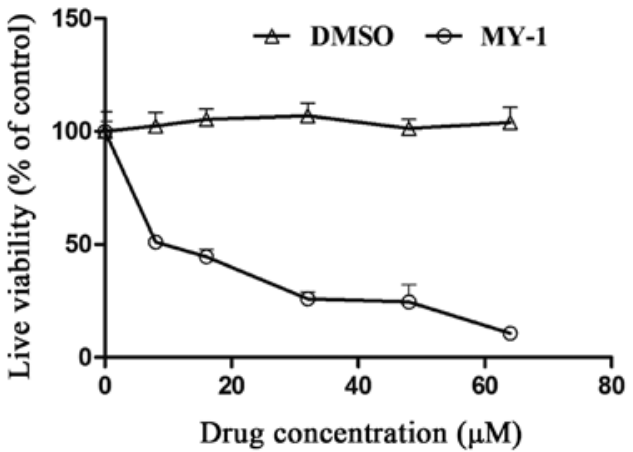

Figure 2. Cytotoxic effect of cycloartan-24-ene-1 $\alpha, 2 \alpha, 3 \beta$-triol (MY-1) on PC-3 cells. Concentration-dependent effects of MY-1 on the viability of human prostatic cancer PC-3 cells treated for $24 \mathrm{~h}$

antibodies were obtained from Boster Bio-Engineering Ltd. Co. (Hubei, China), whereas the secondary antibodies, namely horseradish peroxidase-conjugated anti-rabbit antibody and horseradish peroxidase-conjugated anti-mouse antibody, were obtained from Santa Cruz Biotechnology (Berkeley, CA, USA). $\beta$-actin was used as an internal control to verify loading of similar amounts of the cell lysates.

Statistical analysis. Data are expressed as means \pm standard deviation (SD). The data were statistically analyzed by one-way ANOVA using the GraphPad software package (GraphPad Software, Inc., USA), and p $<0.05$ was considered to indicate a statistically significant result.

\section{Results}

Identification of cycloartan-24-ene-1 $\alpha, 2 \alpha, 3 \beta$-triol (MY-1). MY-1 was isolated as white plates, which showed a molecular ion peak $[\mathrm{M}]^{+}$at 458.6214 in the high-resolution electrospray ionization mass spectrometry. A total of 30 carbons were resolved in the ${ }^{13} \mathrm{C}$ NMR spectrum. The NMR displayed a pair of doublets at $\delta_{\mathrm{H}} 0.52$ and $0.73(\mathrm{~J}=4.3 \mathrm{~Hz})$, characteristic of the cyclopropane ring of a cycloartane triterpene. By comparison of the NMR data with those of cycloartan-24-ene-1 $\alpha, 2 \alpha, 3 \beta$-triol (21), MY-1 was deduced to be cycloartan-24-ene-1 $\alpha, 2 \alpha, 3 \beta$-triol (Fig. 1).

Cytotoxic effect of MY-1 on PC-3 cells. The cytotoxic effect of MY-1 on PC-3 cells was assayed. As shown in Fig. 2, after treatment for $24 \mathrm{~h}$, the cell viability of PC-3 cells was decreased 
$\mathbf{A}$

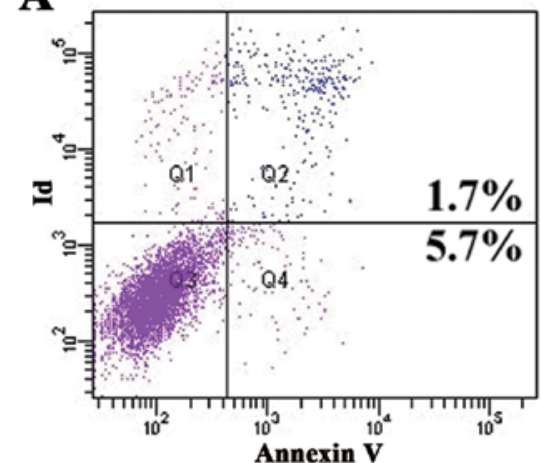

C

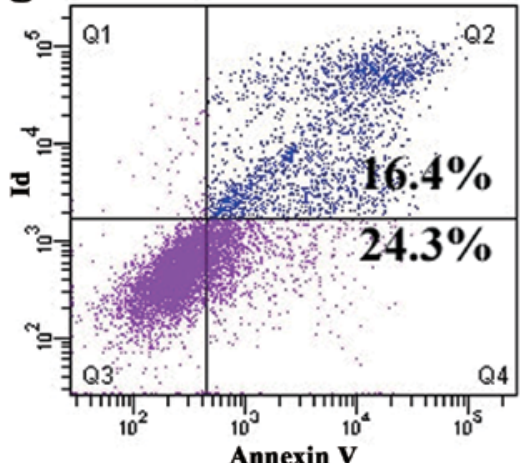

B

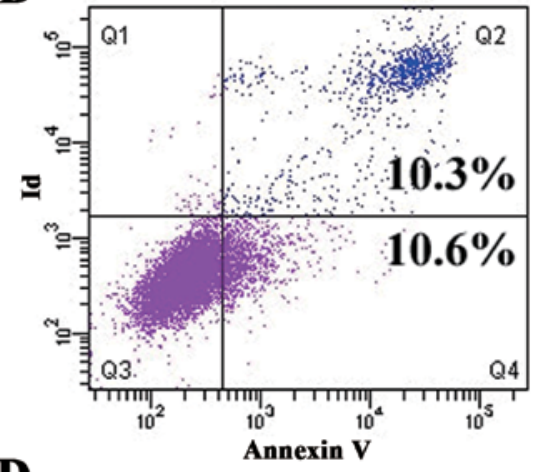

D

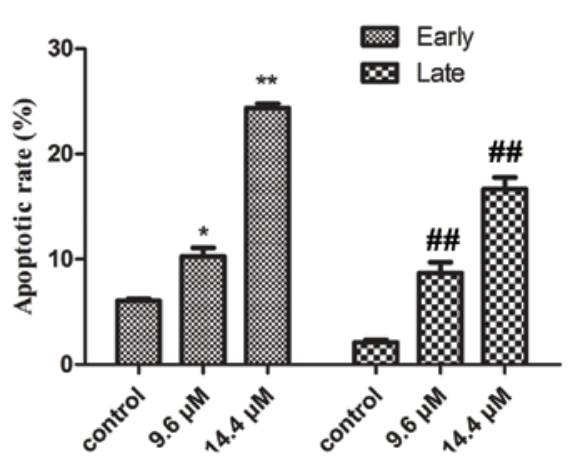

Figure 3. Effect of cycloartan-24-ene-1 $\alpha, 2 \alpha, 3 \beta$-triol (MY-1) on apoptosis in PC-3 cells. Flow cytometric analysis of apoptosis in PC-3 cells treated with MY-1 for $24 \mathrm{~h}$. Extent of apoptosis was measured by staining with Annexin V-FITC/PI. (A) Control. PC-3 cells treated with (B) 9.6 and (C) $14.4 \mu \mathrm{M}$ MY-1 for $24 \mathrm{~h}$. (D) Histogram of the results.

in a concentration-dependent manner. The $\mathrm{IC}_{50}$ value $(50 \%$ inhibitory concentration) of MY-1 was $9.6 \pm 1.3 \mu \mathrm{M}$.

Effect of MY-1 on the apoptosis of PC-3 cells. To confirm and quantify the apoptosis induced by MY-1 in PC3 cells, the cell groups were either untreated or treated with MY-1 (9.6 and $14.4 \mu \mathrm{M}$ ) for $24 \mathrm{~h}$. The cells were then stained with Annexin V-FITC/PI and analyzed by flow cytometry. In the dual-parameter fluorescent dot plots, the cells in early apoptosis (Annexin $\mathrm{V}^{+} / \mathrm{PI}^{-}, \mathrm{Q}_{4}$ ) and in late apoptosis (Annexin $\mathrm{V}^{+} / \mathrm{PI}^{+}, \mathrm{Q}_{2}$ )

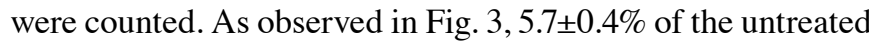
cells were Annexin $\mathrm{V}^{+} / \mathrm{PI}^{-}$, and $1.7 \pm 0.35 \%$ of the untreated cells were Annexin $\mathrm{V}^{+} / \mathrm{PI}^{+}$. The percentages of Annexin $\mathrm{V}^{+} / \mathrm{PI}^{-}$cells after treatment with 9.6 and 14.4 $\mu \mathrm{M}$ MY-1 were $10.6 \pm 1.77$ and $24.3 \pm 1.43 \%(\mathrm{p}<0.05)$, respectively, and the percentages of Annexin $\mathrm{V}^{+} / \mathrm{PI}^{+}$cells were $10.3 \pm 1.91$ and $16.4 \pm 0.74 \%(\mathrm{p}<0.01)$, respectively. These results demonstrated that MY-1 exerts its antitumor activity through the induction of apoptotic cell death.

Observation of the cell morphology. To further confirm the results obtained by flow cytometric analysis, TUNEL assay was used to analyze the apoptotic morphological changes in the PC-3 cells treated with MY-1. After staining, the apoptotic dead cells, which showed a green fluorescence (TUNELpositive), were distinguished from normal cells, and these changes were observed to be concentration-dependent (Fig. 4).

Loss of mitochondrial membrane potential $(\Delta \Psi m)$. To explore whether the MY-1-induced apoptosis is triggered by the mito- chondrial apoptotic pathway, JC-1 staining was used to explore the changes in the $\Delta \Psi \mathrm{m}$ in MY-1-treated PC-3 cells. As observed in Fig. 5, after treatment with 9.6 and 14.4 $\mu \mathrm{M}$ MY-1 for $24 \mathrm{~h}$, the percentages of cells with green fluorescence were 11 and $19 \%$, respectively, compared with $1 \%$ in the untreated cells. These results further suggest that the mitochondrialmediated signaling mechanisms induced by MY-1 triggered the induction of apoptosis in prostate cancer PC-3 cells.

Effect of MY-1 on cell cycle distribution. To examine the effect of MY-1 on cell cycle regulation, PC-3 cells were incubated with different concentrations of MY-1 (9.6 and 14.4 $\mu \mathrm{M})$ for $24 \mathrm{~h}$. After being stained with PI, the cells were analyzed for DNA content by flow cytometry. After exposure to MY-1, the percentage of cells in the G0/G1 phase increased from 63.2 (control) to $71.4 \%(9.6 \mu \mathrm{M})$, and $74.3 \%(14.4 \mu \mathrm{M})$, respectively. The $\mathrm{S}$ phase fraction decreased from 17.5 to $15.7 \%$, and $10.7 \%$ with a concomitant decrease in the G2/M phase (Fig. 6). This result suggests that MY-1 treatment interfered with cell cycle progression and cell division in PC-3 cells.

Effect of MY-1 on the expression of p53, caspase-3, Bcl-2 and Bax proteins. Exposure to cellular and genotoxic stresses can trigger the tumor suppressor protein p53, which is a sequence-specific transcription factor, to induce apoptosis via the regulation of its various downstream proteins. As shown in Fig. 7, the expression of p53 was activated by MY-1 treatment in a dose-dependent manner.

Bcl-2 and Bax are two proteins that play vital roles in the apoptotic process (39). The expression of the pro-apoptotic 


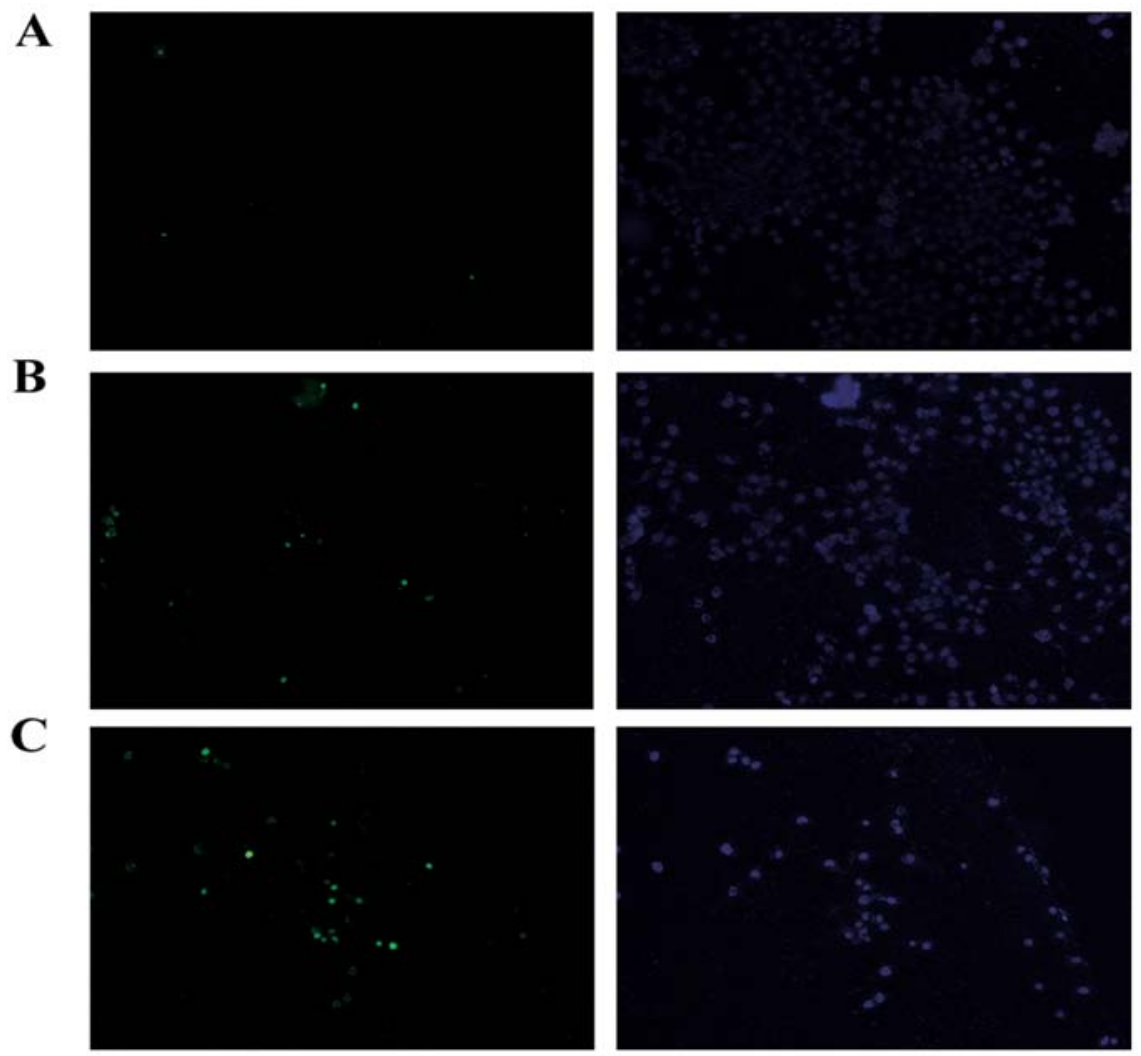

Figure 4. Effect of cycloartan-24-ene-1 $\alpha, 2 \alpha, 3 \beta$-triol (MY-1) on the apoptotic morphological changes in PC-3 cells. Apoptotic morphological changes in PC-3 cells treated with MY-1 were determined by terminal deoxynucleotidyl transferase dUTP nick end-labeling (TUNEL) assay. Cells were cultured in 6-well plates. (A) Control and (B and C) treatment groups. The apoptotic cells (green fluorescent) are TUNEL-positive cells.
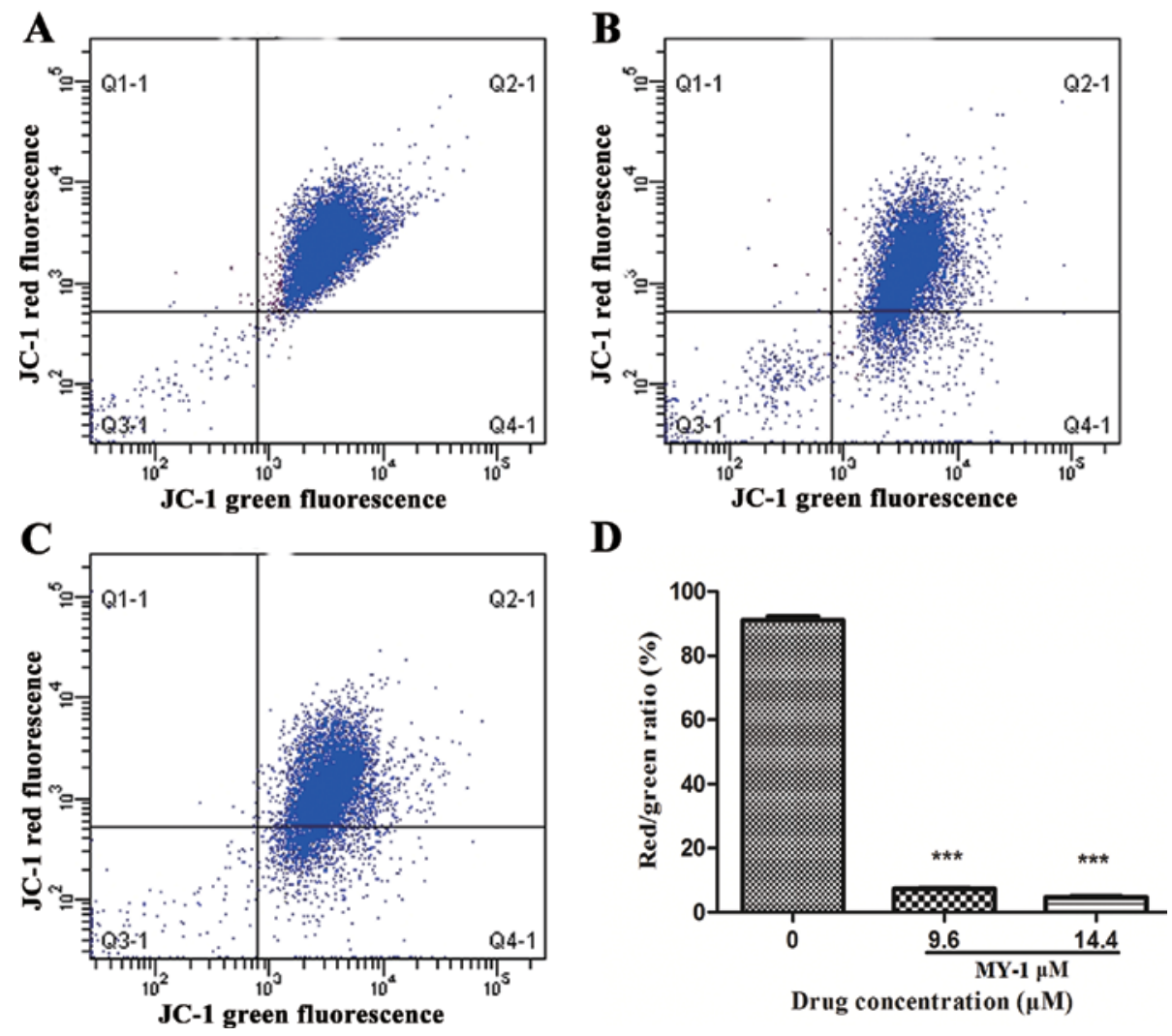

Figure 5. Effects of cycloartan-24-ene-1 $\alpha, 2 \alpha, 3 \beta$-triol (MY-1) on the mitochondrial membrane potential $(\Delta \Psi \mathrm{m})$ in prostate cancer PC-3 cells. Flow cytometric analysis was carried out to detect the mitochondrial membrane potential in PC-3 cells treated with MY-1 (9.6 and $14.4 \mu \mathrm{M}$ ) for $24 \mathrm{~h}$. (A) Control. PC-3 cells treated with (B) 9.6 and (C) $14.4 \mu \mathrm{M}$ MY-1 for $24 \mathrm{~h}$. (D) Quantitative $\Delta \Psi \mathrm{m}$ is expressed as the ratio of red fluorescence intensity to green fluorescence intensity. **** $<0.001$ 
A

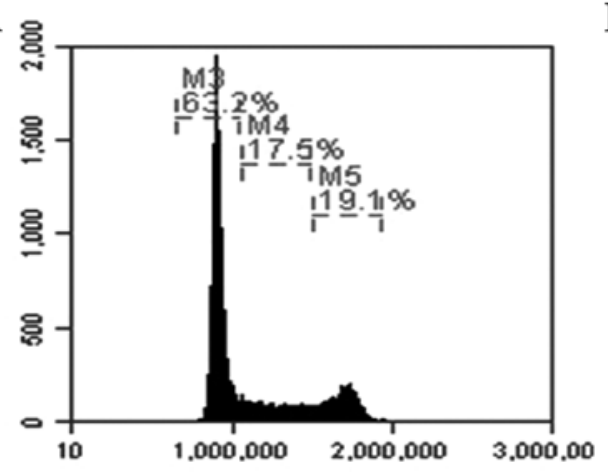

B

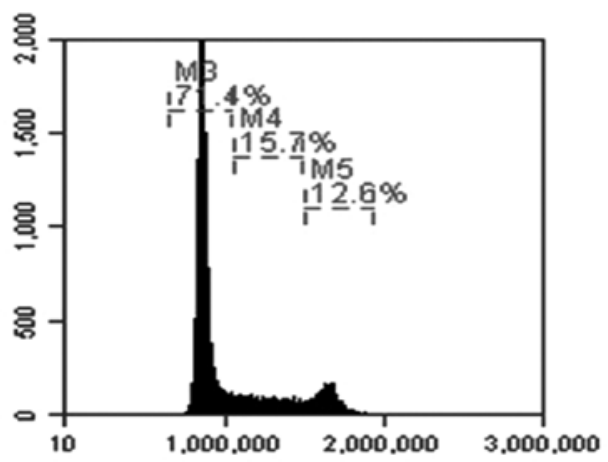

C
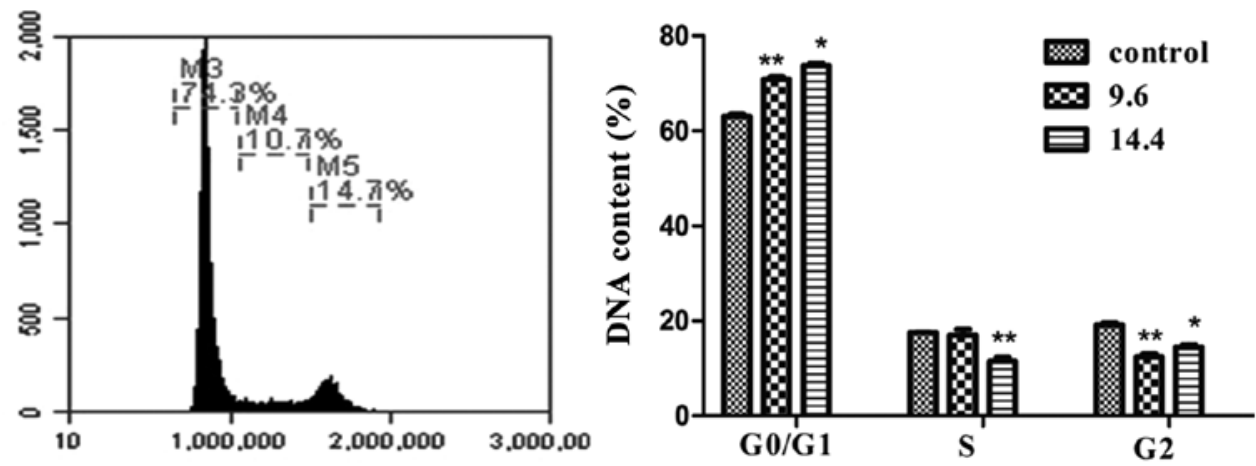

Figure 6. Effect of cycloartan-24-ene-1 $\alpha, 2 \alpha, 3 \beta$-triol (MY-1) on cell cycle changes in PC-3 cells. Cells were collected at the indicated time points and then stained with propidium iodide for analysis by flow cytometry. (A) Control. PC-3 cells treated with (B) 9.6 and (C) $14.4 \mu \mathrm{M} \mathrm{MY}-1$ for $24 \mathrm{~h}$. "p $<0.05$, ${ }^{* * *} \mathrm{p}<0.01$.
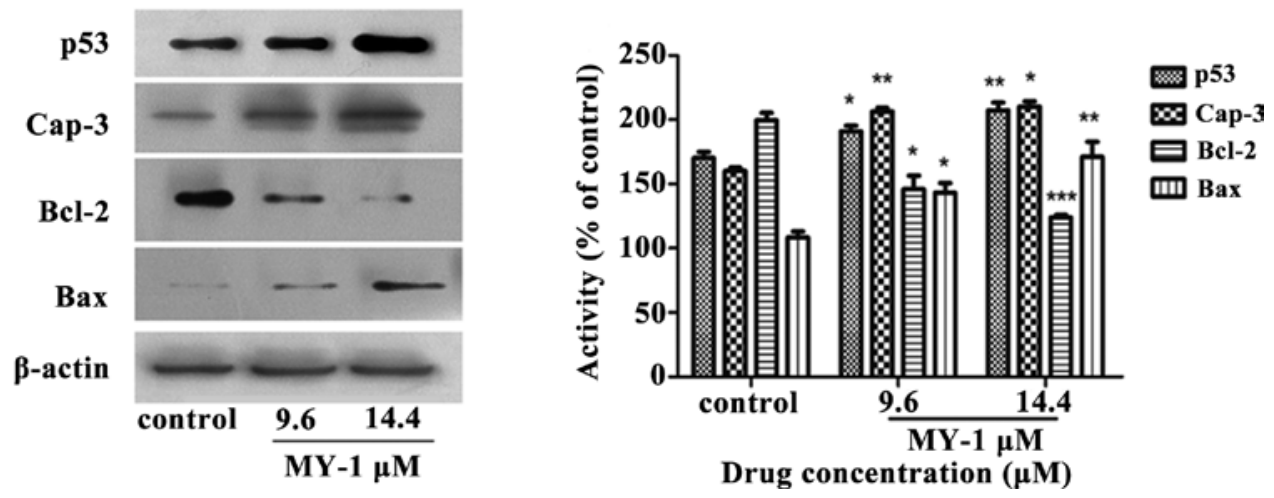

Figure 7. Effects of cycloartan-24-ene-1 $\alpha, 2 \alpha, 3 \beta$-triol (MY-1) on the levels of p53, caspase-3, B-cell lymphoma 2 (Bcl-2) and Bcl-2-associated X protein (Bax) in PC-3 cells. Whole-cell lysates were prepared from PC-3 cells incubated with MY-1 for 24 h. Protein levels were detected by western blotting. $\beta$-actin was used as an internal control. The results are representative of three independent experiments. ${ }^{*} \mathrm{p}<0.05,{ }^{* *} \mathrm{p}<0.01,{ }^{* * *} \mathrm{p}<0.001$.

protein Bax was significantly upregulated by MY-1 treatment, whereas the expression of the anti-apoptotic protein Bcl-2 was downregulated. Based on these results, MY-1 induced apoptosis through the regulation of apoptosis-associated proteins.

\section{Discussion}

Some studies have reported that tetracyclic triterpenoids isolated from C. opobalsamum exert antiproliferative effects on various cancer cells $(21,22)$. The purpose of the present study was to evaluate the cytotoxic effect of one tetracyclic triterpenoid (MY-1) from C. myrrha and investigate whether MY-1 induces apoptosis in human prostate cancer through the mitochondrial pathway.
In the present study, the chemical structure of MY-1 was found to be similar to other reported cycloartane-type triterpenoids $(21,22)$ however, a thorough examination of MY-1 revealed that the locations of the $\mathrm{C}-24$ and $\mathrm{C}-25$ are different. We assume that the mechanisms of action of cycloartane-type triterpenoids on human cancer cells are similar, yet the occurrence of certain structures at C-24 and C-25 may make the bioactivity of these cycloartane-type triterpenoids different from each other. Although the pro-apoptotic effects of MY-1 on the growth of PC-3 cells have been reported (22), the possible mechanism of action through which it induces apoptosis in PC-3 cells is still unknown.

In the present study, the MTT results showed that MY-1 had a moderate cytotoxic effect against PC-3 cells. The 
flow cytometric analyses demonstrated cell cycle arrest at G0/G1 phase and the characteristic morphological changes further confirmed that apoptosis was induced by MY-1 (Figs. 3, 4 and 6). It has been demonstrated that the activation of the anti-oncogene p53 plays an important role in the suppression of the formation of cancer. Increased expression of the p53 protein may lead to DNA damage in PC-3 cells after treatment with MY-1. Further experiments in the present study also showed that MY-1 treatment notably decreased the expression of the anti-apoptotic Bcl-2 protein and increased the expression of the pro-apoptotic Bax protein. These findings confirm the hypothesis that the MY-1-induced apoptosis in PC-3 cells is triggered by the downregulation of $\mathrm{Bcl}-2$ and the upregulation of Bax. In addition, the experimental results also revealed that MY-1 treatment induced a concentrationdependent activation of caspase-3, which is a key executioner of apoptosis (Fig. 7). The observed loss of $\Delta \Psi \mathrm{m}$ (Fig. 5) clarified that the mitochondrial-mediated pathway may be at least one of the mechanisms responsible for the induction of apoptosis.

This study has some limitations. It is preliminary in nature and as such we did not compare the action of MY-1 with other similar compounds that have also been shown to have anticancer potential. The action of MY-1 on other cell lines would be of interest, as we can provide no conclusions concerning whether the apoptotic action on PC-3 cells is unique or could be replicated in cells that for example express the prostatespecific antigen or on non-cancerous cell lines.

In conclusion, a tetracyclic triterpenoid (MY-1) was isolated from C. myrrha. The MY-1 compound has potential anticancer activity through its induction of apoptosis in PC-3 cells. The mechanism of the apoptosis induction is probably through the mitochondrial-initiated pathway. As a potential candidate in the field of anticancer drug discovery against human prostatic cancer, the in vivo activity of MY-1 in an animal model of prostate cancer warrants investigation.

\section{Acknowledgements}

This study was supported by the Action Plan Project for the Enterprise of the Ministry of Science and Technology of China (2009CB522808), the Natural Science Foundation of Jiangsu Province (BK2008194), the Jiangsu Overseas Research and Training Program for University Prominent Young and Middle-Aged Teachers and Presidents, and the Science and Technology Project of the Department of Traditional Chinese Medicines in Jiangsu Province (LZ11163).

\section{References}

1. Kerr JF, Wyllie AH and Currie AR: Apoptosis: a basic biological phenomenon with wide-ranging implications in tissue kinetics. Br J Cancer 26: 239-257, 1972.

2. Luo KW, Sun JG, Chan JY, et al: Anticancer effects of imperatorin isolated from Angelica dahurica: induction of apoptosis in HepG2 cells through both death-receptor- and mitochondriamediated pathways. Chemotherapy 57: 449-459, 2011.

3. Gottlieb E, Armour SM, Harris MH and Thompson CB: Mitochondrial membrane potential regulates matrix configuration and cytochrome $c$ release during apoptosis. Cell Death Differ 10: 709-717, 2003.

4. Creagh EM and Martin SJ: Caspases: cellular demolition experts Biochem Soc Trans 29: 696-702, 2001.
5. Porter AG and Jänicke RU: Emerging roles of caspase-3 in apoptosis. Cell Death Differ 6: 99-104, 1999.

6. Amundson SA, Myers TG and Fornace AJ Jr: Roles for p53 in growth arrest and apoptosis: putting on the brakes after genotoxic stress. Oncogene 17: 3287-3299, 1998.

7. Los M, Wesselborg S and Schulze-Osthoff K: The role of caspases in development, immunity, and apoptotic signal transduction: lessons from knockout mice. Immunity 10: 629-639, 1999.

8. Wijesekara I, Zhang C, Van Ta Q, Vo TS, Li YX and Kim SK: Physcion from marine-derived fungus Microsporum sp. induces apoptosis in human cervical carcinoma HeLa cells. Microbiol Res 169: 255-261, 2014.

9. Wang M, Huang T, Zeng F, et al: Effect of Smac on TRAILinduced apoptosis of prostate cancer cell line PC-3 and the molecular mechanism. J Huazhong Univ Sci Technolog Med Sci 32: 233-236, 2012.

10. Tian Z, Liu YM, Chen SB, et al: Cytotoxicity of two triterpenoids from Nigella glandulifera. Molecules 11: 693-699, 2006.

11. da Rocha AB, Lopes RM and Schwartsmann G: Natural products in anticancer therapy. Curr Opin Pharmacol 1: 364-369, 2001.

12. Cheng X, Xiao Y, Wang P, et al: The ethyl acetate fraction of Polytrichum commune L.ex Hedw induced cell apoptosis via reactive oxygen species in L1210 cells. J Ethnopharmacol 148: 926-933, 2013.

13. Cragg GM and Newman DJ: Plants as a source of anti-cancer agents. J Ethnopharmacol 100: 72-79, 2005.

14. Gordaliza M: Natural products as leads to anticancer drugs. Clin Transl Oncol 9: 767-776, 2007.

15. Nobili S, Lippi D, Witort E, et al: Natural compounds for cancer treatment and prevention. Pharmacol Res 59: 365-378, 2009.

16. Su SL, Duan JA, Tang YP, et al: Isolation and biological activities of neomyrrhaol and other terpenes from the resin of Commiphora myrrha. Planta Med 75: 351-355, 2009.

17. Abbas FA, Al-Massarany SM, Khan S, Al-Howiriny TA, Mossa JS and Abourashed EA: Phytochemical and biological studies on Saudi Commiphora opobalsamum L. Nat Prod Res 21: 383-391, 2007.

18. Shen T, Li GH, Wang XN and Lou HX: The genus Commiphora: a review of its traditional uses, phytochemistry and pharmacology. J Ethnopharmacol 142: 319-330, 2012.

19. Shoemaker M, Hamilton B, Dairkee SH, Cohen I and Campbell MJ: In vitro anticancer activity of twelve Chinese medicinal herbs. Phytother Res 19: 649-651, 2005.

20. Yuan H, Pan Y and Young CY: Overexpression of c-Jun induced by quercetin and resverol inhibits the expression and function of the androgen receptor in human prostate cancer cells. Cancer Lett 213: 155-163, 2004

21. Shen T, Wan W, Yuan H, et al: Secondary metabolites from Commiphora opobalsamum and their antiproliferative effect on human prostate cancer cells. Phytochemistry 68: 1331-1337, 2007.

22. Shen T, Yuan HQ, Wan WZ, et al: Cycloartane-type triterpenoids from the resinous exudates of Commiphora opobalsamum. J Nat Prod 71: 81-86, 2008.

23. Xu R, Fazio GC and Matsuda SP: On the origins of triterpenoid skeletal diversity. Phytochemistry 65: 261-291, 2004.

24. Yang JL and Shi YP: Cycloartane-type triterpenoids and sesquiterpenoids from the resinous exudates of Commiphora opobalsamum. Phytochemistry 76: 124-132, 2012.

25. Qiu J, Gao Z and Shima H: Growth of human prostate cancer cells is significantly suppressed in vitro with sodium butyrate through apoptosis. Oncol Rep 27: 160-167, 2012.

26. Liu YQ, Hu XY, Lu T, et al: Retigeric acid B exhibits antitumor activity through suppression of nuclear factor- $\mathrm{\kappa} B$ signaling in prostate cancer cells in vitro and in vivo. PLoS One 7: e38000, 2012.

27. Ghosh $\mathbf{J}$ and Myers CE: Inhibition of arachidonate 5-lipoxygenase triggers massive apoptosis in human prostate cancer cells. Proc Natl Acad Sci USA 95: 13182-13187, 1998.

28. Tan C, Cai LQ, Wu W, et al: NSC606985, a novel camptothecin analog, induces apoptosis and growth arrest in prostate tumor cells. Cancer Chemother Pharmacol 63: 303-312, 2009.

29. Marcelli M, Marani M, Li X, et al: Heterogeneous apoptotic responses of prostate cancer cell lines identify an association between sensitivity to staurosporine-induced apoptosis, expression of Bcl-2 family members, and caspase activation. Prostate 42: 260-273, 2000. 
30. Ahmad KA, Harris NH, Johnson AD, Lindvall HC, Wang G and Ahmed K: Protein kinase CK2 modulates apoptosis induced by resveratrol and epigallocatechin-3-gallate in prostate cancer cells. Mol Cancer Ther 6: 1006-1012, 2007.

31. Hahm ER, Arlotti JA, Marynowski SW and Singh SV: Honokiol, a constituent of Oriental medicinal herb Magnolia officinalis, inhibits growth of PC-3 xenografts in vivo in association with apoptosis induction. Clin Cancer Res 14: 1248-1257, 2008.

32. Lee DH, Szczepanski MJ and Lee YJ: Magnolol induces apoptosis via inhibiting the EGFR/PI3K/Akt signaling pathway in human prostate cancer cells. J Cell Biochem 106: 1113-1122, 2009.

33. Park EJ, Kim SH, Kim BJ, Kim SY, So I and Jeon JH: Menthol enhances an antiproliferative activity of $1 \alpha, 25$-dihydroxyvitamin $\mathrm{D}_{3}$ in LNCaP Cells. J Clin Biochem Nutr 44: 125-130, 2009.

34. Chung BH, Lee HY, Lee JS and Young CY: Perillyl alcohol inhibits the expression and function of the androgen receptor in human prostate cancer cells. Cancer Lett 236: 222-228, 2006.
35. Obasaju C and Hudes GR: Paclitaxel and docetaxel in prostate cancer. Hematol Oncol Clin North Am 15: 525-545, 2001.

36. Kiviharju TM, Lecane PS, Sellers RG and Peehl DM Antiproliferative and proapoptotic activities of triptolide (PG490), a natural product entering clinical trials, on primary cultures of human prostatic epithelial cells. Clin Cancer Res 8: 2666-2674, 2002.

37. Yang H, Landis-Piwowar KR, Lu D, et al: Pristimerin induces apoptosis by targeting the proteasome in prostate cancer cells. J Cell Biochem 103: 234-244, 2008.

38. Zhang Y, Kong C, Zeng Y, et al: Ursolic acid induces PC-3 cell apoptosis via activation of JNK and inhibition of Akt pathways in vitro. Mol Carcinog 49: 374-385, 2010.

39. Sun JG, Chen CY, Luo KW, et al: 3,5-Dimethyl- ${ }^{7} \mathrm{H}$-furo[3,2-g] chromen-7-one as a potential anticancer drug by inducing p53-dependent apoptosis in human hepatoma HepG2 cells. Chemotherapy 57: 162-172, 2011. 